\title{
Contemporary outcomes of surgical ventricular septal defect closure
}

\author{
Brett R. Anderson, MD, MBA, ${ }^{a}$ Kristen N. Stevens, PhD, ${ }^{b}$ Susan C. Nicolson, MD, \\ Stephen B. Gruber, MD, PhD, ${ }^{\text {dee }}$ Thomas L. Spray, MD,${ }^{f}$ Gil Wernovsky, MD, ${ }^{\text {a,g }}$ and \\ Peter J. Gruber, MD, $\mathrm{PhD}^{\mathrm{f}}$
}

Objectives: Surgical closure of ventricular septal defects remains the most common pediatric cardiac surgical procedure. No studies, however, have comprehensively analyzed risk factors and drivers of nonmortality outcomes in the current era. The purpose of this study was to assess both baseline characteristics and outcomes of children undergoing surgical repair of ventricular septal defects in a contemporary cohort.

Methods: This retrospective study examined a consecutive series of 369 ventricular septal defect closures at a single institution. Because mortality is low in nearly all centers for repair of these defects, we focused on morbidity and identified drivers of risk via multivariable linear regression modeling.

Results: For children younger than age 6 months undergoing ventricular septal defect closure, every extra kilogram in operative weight results in a 2.3-day shorter length of stay. In an analysis of composite risk, patients younger than age 6 months undergoing ventricular septal defect repair exhibited a 1.8-fold increase in composite risk for each kilogram decrease in weight, whereas patients older than age 6 months experienced no significant difference.

Conclusions: Even in the current surgical era, weight remains a significant predictor of morbidity and driver or length of stay in young infants undergoing ventricular septal defect closure. Weight still should be considered when discussing operative risks for children younger than age 6 months undergoing this procedure, irrespective of the indication for operation. (J Thorac Cardiovasc Surg 2013;145:641-7)

Isolated ventricular septal defects (VSDs) are the most common congenital structural heart disease, occurring in 0.34 to 2.68 per 1000 live births. ${ }^{1-3}$ Although $80 \%$ of patients with VSDs presenting before age 1 month will have spontaneous closure of the defect, patients in whom closure does not occur often require surgery. ${ }^{4}$ Surgical closure of VSDs remains the most common pediatric cardiac surgical procedure, and there have been continued advances in surgical and medical care since Lillehei and colleagues ${ }^{5,6}$ performed the first successful repair in 1957, yet surprisingly few studies have been published during the past decade evaluating postoperative morbidity and

\footnotetext{
From the Departments of Pediatrics, ${ }^{\mathrm{a}}$ Anesthesia and Critical Care Medicine, ${ }^{\mathrm{c}}$ Division of Cardiology, ${ }^{\mathrm{g}}$ and Division of Pediatric Cardiothoracic Surgery ${ }^{\mathrm{f}}$ at The Children's Hospital of Philadelphia and University of Pennsylvania School of Medicine, Philadelphia, Pa; and the Departments of Medicine, ${ }^{\mathrm{d}}$ Epidemiology, and the Division of Molecular Medicine and Genetics ${ }^{\mathrm{e}}$ at the University of Michigan, Ann Arbor, Mich.

Disclosures: Authors have nothing to disclose with regard to commercial support.

Read at the 36th Annual Meeting of the Western Thoracic Surgical Association, Ojai, California, June 23-26, 2010.

Dr Anderson's current affiliation is with the Division of Pediatric Cardiology, NewYork-Presbyterian/Morgan Stanley Children's Hospital, New York, NY.

Drs Anderson and Stevens contributed equally to this article.

Received for publication Feb 9, 2011; revisions received Sept 28, 2012; accepted for publication Nov 9, 2012.

Address for reprints: Peter J. Gruber, MD, PhD, Section of Pediatric Cardiothoracic Surgery, Primary Children's Medical Center, The University of Utah School of Medicine, Suite 2800, 100 North Mario Capecchi Dr, Salt Lake City, UT 84113 (E-mail: peter.gruber@hsc.utah.edu).

$0022-5223 / \$ 36.00$

Copyright (c) 2013 by The American Association for Thoracic Surgery

http://dx.doi.org/10.1016/j.jtcvs.2012.11.032
}

mortality for VSD closure, ${ }^{7-12}$ and even fewer that comprehensively analyze current risk factors and drivers of outcomes. ${ }^{4,13-15}$ The purpose of this study was to assess baseline characteristics of and outcomes for children undergoing surgical repair of simple VSDs in a contemporary cohort, as well as to determine drivers of these outcomes. We performed a retrospective chart review of a consecutive surgical series $(n=369)$ of simple VSD closures at a single large institution. Because mortality is low in nearly all centers for repair of VSD, we focused on morbidity and identified drivers of risk via multivariable linear regression modeling, with secondary analysis focusing on length of stay.

\section{METHODS \\ Patient Population}

This retrospective study examined a consecutive series of 369 surgical patients presenting to the Children's Hospital of Philadelphia for surgical closure of simple VSD between January 1, 2002, and December 31, 2008. Patients with a concomitant atrial septal defect, patent ductus arteriosus, patent foramen ovale, coarctation of the aorta, or stenotic/regurgitant semilunar valves were included. Patients with all other complex cardiac anomalies, including tetralogy of Fallot and double outlet right ventricle, were excluded. Patients who had undergone previous pulmonary artery banding were included in this study. The medical records for these patients were retrospectively reviewed with permission from the Children's Hospital of Philadelphia Institutional Review Board.

Of 369 patients initially identified from the surgical database, 84 were excluded because of incomplete data sets (mostly related to perfusion data). A combination of echocardiography reports, clinic, inpatient, and operative notes were reviewed. Outcomes were assessed through the first postoperative visit. 


\section{Abbreviations and Acronyms \\ $\mathrm{VSD}=$ ventricular septal defect \\ $\mathrm{ECMO}=$ extracorporeal membrane oxygenation \\ TEE $=$ transesophageal echocardiogram \\ TTE $=$ transthoracic echocardiogram}

Preoperative characteristics, including sex, race, gestational age, birth weight, age at operation, weight at operation, days in hospital preoperation, days ventilated preoperation, type of VSD, size of VSD, operative indication, product of multiple gestation or in-vitro fertilization, maternal history of diabetes, underlying genetic condition, and comorbid noncardiac medical conditions, were assessed. The sizes of preoperative and residual VSDs were recorded from the official interpretation by staff echocardiographers. VSD size was categorized as "small" (<3 mm), "moderate" (3-5 mm), "large" (6-9 mm), and "very large" $(>10 \mathrm{~mm})$. In the setting of multiple VSDs, size was recorded as the sum of the total sizes. The magnitude of semilunar valvar insufficiency was determined by review of reports by staff echocardiographers. The indications for operation was classified into 1 of 3 mutually exclusive groups: (1) failure to thrive/congestive heart failure (Category Q: "Flow"); (2) right ventricular obstruction, aortic insufficiency, or double chamber right ventricle (Category O: "Obstruction"); and (3) elevated pulmonary vascular resistance (Category P: "Pulmonary"). Although some overlap was inevitable, patients were separated into the diagnostic group for which they were referred for operation by their primary cardiologists. A diagnosis of failure to thrive was determined by the primary cardiologist and generally based on clinical criteria, including weight less than the fifth percentile for age or crossing 2 major percentile channels; all patients carrying the diagnosis of failure to thrive had been prescribed either diuretics or digoxin, or both, and were receiving fortified feeds. A diagnosis of heart failure was made based on a combination of subjective signs and symptoms, diagnosed by the referring cardiologist, including feeding or exercise intolerance, significant ascites, or hepatomegaly. A diagnosis of obstruction was made by echocardiography. A diagnosis of rising pulmonary vascular resistance was made by either cardiac catheterization or echocardiography.

Operative factors, including crossclamp, bypass, and total operation times, as well as surgical technique (patch closure vs primary closure) were also assessed as drivers of outcomes, including length of stay, incidence of reoperation, wound infection, postpericardiotomy syndrome, chylous effusion, chest tube, transient or complete heart block, seizure, rehospitalization, extracorporeal membrane oxygenation (ECMO), and death. A composite factor of major adverse events was also assessed, defined as death, cardiac arrest, ECMO, reoperation, stroke, or heart block necessitating a permanent pacemaker.

\section{Surgical Technique}

All patients underwent median sternotomy. Cardiopulmonary bypass was used for all patients. Circulatory arrest was rare. All operations were performed by 1 of 7 surgeons at the Children's Hospital of Philadelphia ( $98 \%$ of surgeries were performed by the same 3 surgeons). Primary or Dacron patch closure, using either interrupted (rare) or running techniques (most), was employed at surgeons' discretion. Concomitant infundibular muscle resection, valvuloplasty, vascular ring repair, atrial septal defect repair, patent foramen ovale closure, patent ductus arteriosus ligation, and/or division were performed when indicated. Modified ultrafiltration was used in all patients. All patients received a preoperative transthoracic echocardiogram and either intraoperative transesophageal echocardiogram $(95.1 \%)$ or postoperative transthoracic echocardiogram $(90.9 \%)$ at the surgeon's discretion.

\section{Statistical Methods}

All statistical analyses were conducted in SAS (version 9.1. SAS Institute, Inc, Cary, NC). Descriptive statistics were computed for demographic and clinical variables using means, medians, and standard deviations for continuous variables, and frequency tables for categorical variables. One-way analysis of variance was used to measure the associations between indication for operation and continuous variables. Fisher's exact test was used to measure associations with categorical variables. Length of stay was $\log _{10}$-transformated to include in correlations and regression models. Parameter estimates were then back-transformed to correspond to length of stay. Residuals of regression models were examined, using $\log _{10}$-transformation of length of stay, and no substantial deviance from normality was observed. Relationships between length of stay in the hospital and continuous or categorical variables were measured using Pearson correlation coefficients and unpaired $t$ tests, respectively. A multivariable linear regression model of length of stay was built using variables significantly associated with length of stay in univariable analyses, assessing fit by adjusted $R^{2}$. The results from stepwise regression were consistent with this analysis. Associations between the composite end point and various predictors were assessed using logistic regression.

\section{RESULTS \\ Descriptive Characteristics}

We analyzed demographic information for 285 patients who met inclusion criteria (Table 1). Boys and girls were equally represented ( $51.6 \%$ boys, $0.7 \%$ ambiguous genitalia). A majority of patients were white $(61.4 \%)$, followed by black (16.5\%), Hispanic (7.0\%), and Asian (3.5\%). A majority of patients $(71.2 \%)$ were aged $<12$ months, with more than half $(57.9 \%)$ younger than age 6 months. The median age was 144 days (range, 16 days to 48.5 years) (Appendix Table 1). Somewhat surprisingly, an underlying genetic syndrome was present in $25.6 \%$ of patients, of whom $49.3 \%$ had Trisomy 21 (12.6\% of the total cohort). Six percent were products of twin or triplet gestation (vs $2.6 \%$ of all live US births), $2.5 \%$ were products of in vitro fertilization, and $2.8 \%$ were infants of mothers with insulin-dependent diabetes.

For most patients, the primary indication for operation was failure to thrive/congestive heart failure $(81.4 \%)$. The next most common indication was right ventricular obstruction, aortic insufficiency, or double chamber right ventricle $(11.0 \%)$, followed by rising pulmonary vascular resistance $(7.8 \%)$. Anatomic VSD types were represented as follows: $8.4 \%$ single conoseptal (Type I), $77.9 \%$ single conoventricular (Type II), $1.8 \%$ single inlet/canal type (Type III), $2.8 \%$ single muscular (Type IV), and $9.1 \%$ multiple. Of the total cohort, $15.1 \%$ were associated with a patent ductus arteriosus, $33.7 \%$ with a patent foramen ovale, and $22.8 \%$ with 1 or more atrial septal defect. One patient had associated partial anomalous venous return (Table 2).

Hospital and operative characteristics were also examined (Appendix Table 1 and Table 2). Of the patients, $22.6 \%$ were inpatients preoperatively; $10.2 \%$ were transferred from outside hospitals for the operation. Preoperative ventilation was a characteristic of $2.8 \%$ of patients. Mean operative time was $122.9 \pm 34.9$ minutes 
TABLE 1. Patient demographics $(n=285)$

\begin{tabular}{lc}
\hline \multicolumn{1}{c}{ Variable } & $\mathbf{n}(\%)$ \\
\hline Sex & \\
Boy & $147(51.6)$ \\
Girl & $136(47.8)$ \\
Ambiguous & $2(0.8)$ \\
Age & \\
$<30$ d & $8(2.8)$ \\
30 d-12 mo & $203(71.2)$ \\
12 mo-18 y & $73(25.6)$ \\
$>18$ y & $1(0.4)$ \\
Age category (mo) & \\
$\leq 6$ & $165(57.9)$ \\
$>6$ & $120(42.1)$ \\
Race/ethnicity & \\
Asian & $10(3.5)$ \\
Black & $47(16.5)$ \\
White & $175(61.4)$ \\
Hispanic & $20(7.0)$ \\
Other & $33(11.6)$ \\
Genetic syndrome & \\
Trisomy 21 & $36(12.6)$ \\
22q11 & $9(3.2)$ \\
Trisomy 18 mosaic & $3(1.1)$ \\
Other trisomy mosaic & $3(1.1)$ \\
Other & $22(7.8)$ \\
\hline
\end{tabular}

(range, 5-336 minutes). Mean cardiopulmonary bypass time was $46.1 \pm 25$ minutes (range, 16-221 minutes). Mean aortic crossclamp time was $27.6 \pm 13.9$ minutes (range 8-87 minutes). Neither bypass time nor crossclamp time changed during the 7 years of this study, regardless of indication for surgery or age at operation (Appendix Tables 2 and 3), although modified ultrafiltration time decreased over time for patients of all ages in category $\mathrm{Q}\left(R^{2}, 0.093\right.$; $P<.0001)$. For children younger than age 6 months, indication for operation was not correlated with time in the operating room, time from incision, bypass time, or crossclamp time.

All patients had either an intraoperative transesophageal echocardiogram (TEE) $(95.1 \%$ ), a postoperative transthoracic echocardiogram (TTE) $(90.9 \%$ ), or both. Mean total residual VSD on TEE was $0.6 \pm 1.0 \mathrm{~mm}$ and on TTE was $1.1 \pm 1.3 \mathrm{~mm}$, correlating well with previously published studies of differences between TTE and TEE analyses. After TEE, 9 patients $(3.2 \%)$ had second pump runs; $8(2.8 \%)$ of these to address residual or additional defects. There was no association between residual VSD size and age, weight, or operative indication.

Eighty percent of patients $(n=228)$ were extubated in the immediate postoperative period (within 1 hour of arrival to the intensive care unit). Mean time of intubation for the remaining patients was $3.5 \pm 3.8$ days (range, 1 19 days). Reintubation was required for 13 patients $(4.6 \%) 1$ or more times postoperatively. Mean
TABLE 2. Operative characteristics $(\mathbf{n}=\mathbf{2 8 5})$

\begin{tabular}{|c|c|}
\hline Variable & Result \\
\hline Operative time (min) & $122.9 \pm 34.9 / 119.5(52.0-336.0)$ \\
\hline Bypass time (min) & $46.1 \pm 25.0 / 41.0(16.0-221.0)$ \\
\hline Aortic cross-clamp time (min) & $27.6 \pm 13.9 / 25.0(8.0-87.0)$ \\
\hline Pre-MUF Hct (mg/dL) & $30.2 \pm 3.2 / 30.0(23.0-38.0)$ \\
\hline Post-MUF Hct (mg/dL) & $43.0 \pm 5.5 / 43.0(30.0-63.0)$ \\
\hline MUF time (min) & $8.8 \pm 1.8 / 9.0(0.0-17.0)$ \\
\hline Aortic root diameter $(\mathrm{cm})$ & $1.3 \pm 0.6 / 1.2(0.7-4.6)$ \\
\hline Aortic root ( $z$ score $)$ & $2.3 \pm 10.3 / 1.1(-2.1-76.0)$ \\
\hline \multicolumn{2}{|l|}{ Indication for operation* } \\
\hline FTT/CHF (Category Q) & $232(81.4)$ \\
\hline RVOTO/AI/DCRV (Category O) & $31(10.9)$ \\
\hline PHTN (Category P) & $22(7.7)$ \\
\hline \multicolumn{2}{|l|}{ Ventricular septal defect type } \\
\hline Type 1 (conoseptal) & $30(10.5)$ \\
\hline Type 2 (conoventricular) & $231(81.1)$ \\
\hline Type 3 (inlet/canal type) & $11(3.8)$ \\
\hline Type 4 (muscular) & $11(3.8)$ \\
\hline Multiple & $2(0.7)$ \\
\hline \multicolumn{2}{|l|}{ Repair type } \\
\hline \multicolumn{2}{|l|}{ Type 1} \\
\hline Patch & $21(7.4)$ \\
\hline Primary closure & $9(3.2)$ \\
\hline \multicolumn{2}{|l|}{ Type 2} \\
\hline Patch & $208(73.0)$ \\
\hline Primary closure & $23(8.1)$ \\
\hline \multicolumn{2}{|l|}{ Type 2} \\
\hline Patch & $9(3.2)$ \\
\hline Primary closure & $2(0.7)$ \\
\hline \multicolumn{2}{|l|}{ Type 4} \\
\hline Patch & $9(3.2)$ \\
\hline Primary closure & $2(0.7)$ \\
\hline \multicolumn{2}{|l|}{ Associated cardiac defects } \\
\hline Patent foramen ovale & $96(33.7)$ \\
\hline Atrial septal defect & $65(22.8)$ \\
\hline Patent ductus arteriosus & $43(15.1)$ \\
\hline $\begin{array}{l}\text { Partial anomalous pulmonary } \\
\text { venous return }\end{array}$ & $1(0.4)$ \\
\hline \multicolumn{2}{|l|}{ Gestational factors } \\
\hline Product of multiple gestation & $17(6)$ \\
\hline In vitro fertilization & $7(2.5)$ \\
\hline Infant of a diabetic mother & $8(2.8)$ \\
\hline
\end{tabular}

Data are presented as mean \pm standard deviation/median (minimum-maximum) or n (\%). MUF Hct, Modified ultrafiltration hematocrit; FTT/CHF, failure to thrive/ congestive heart failure; RVOTO/AI/DCRV, right ventricle outflow tract obstruction/aortic insufficiency/double chambered right ventricle; $P H T N$, pulmonary hypertension. *Indication for operation was classified in 1 of 3 mutually exclusive groups: FTT/CHF (Category Q: "Flow"); RVOTO/AI/DCRV (Category O: "Obstruction"); and elevated pulmonary vascular resistance (Category P: "Pulmonary").

postoperative hospital stay was $6.5 \pm 17.5$ days (range 1-269 days).

\section{Adverse Events and Associations}

We examined the prevalence of the following adverse events: reoperation, wound infection, postpericardiotomy syndrome, chylous effusion, chest tube, transient or 
TABLE 3. Event rates by operative indication*

\begin{tabular}{|c|c|c|c|c|c|}
\hline Variable & Overall $(n=285)$ & Category $Q(n=232)$ & Category $P(n=22)$ & Category $O(n=31)$ & Fisher's exact $P$ value \\
\hline Any reoperation & 14 & $10(71.4)$ & $0(0)$ & $4(28.6)$ & .094 \\
\hline Wound infection & 4 & $4(100)$ & $0(0)$ & $0(0)$ & .999 \\
\hline Postpericardiotomy syndrome & 3 & $2(66.7)$ & $0(0)$ & $1(33.3)$ & .466 \\
\hline Chylous effusion & 4 & $2(50.0)$ & $2(50.0)$ & $0(0)$ & $.045 \dagger$ \\
\hline Chest tube & 10 & $7(70.0)$ & $2(20.0)$ & $1(10.0)$ & .254 \\
\hline \multicolumn{6}{|l|}{ Heart block } \\
\hline Transient & 10 & $8(80.0)$ & $2(20.0)$ & $0(0)$ & .197 \\
\hline Permanent, pacemaker placed & 6 & $5(83.3)$ & $0(0)$ & $1(16.7)$ & .717 \\
\hline Seizure & 5 & $5(100.0)$ & $0(0)$ & $0(0)$ & .999 \\
\hline $\begin{array}{l}\text { Extracorporeal membrane } \\
\text { oxygenation }\end{array}$ & 5 & $3(60.0)$ & $0(0)$ & $2(40.0)$ & .143 \\
\hline Death & 5 & $4(80.0)$ & $0(0)$ & $1(20.0)$ & .650 \\
\hline Rehospitalization & 1 & $1(100)$ & $0(0)$ & $0(0)$ & .999 \\
\hline
\end{tabular}

Data are presented as n (\%). *Indication for operation was classified in 1 of 3 mutually exclusive groups: failure to thrive/congestive heart failure (Category Q: "Flow"); right ventricular obstruction, aortic insufficiency, or double chamber right ventricle (Category O: "Obstruction"); and elevated pulmonary vascular resistance (Category P: "Pulmonary"). $\dagger P>.01$ to .05 .

permanent heart block, seizure, rehospitalization, ECMO, or death (Table 3). The most common complications were transient or complete heart block $(5.6 \%)$, followed by reoperation $(4.9 \%)$ and pleural effusion requiring a chest tube $(3.5 \%)$. The proportions of patients with these events, considered individually or combined, were not significantly different by indication for operation. We also examined the composite outcome of major adverse events, defined as reoperation, heart block requiring permanent pacer, cardiac arrest, ECMO, or death. Major adverse events occurred in $5.3 \%$ of patients $(n=15)$. Four patients $(1.4 \%)$ died before discharge, and 1 died at home 6 days after discharge of an unknown reason. All 5 patients who died did so between postoperative days 6 and 10 .

To identify potential predictors of these adverse outcomes, we analyzed their associations in a univariable analysis with measured variables. There were no significant differences in operative time, perfusion time, or crossclamp time for all diagnostic categories $(\mathrm{O}, \mathrm{P}$, or $\mathrm{Q})$ during the course of the 7-year study. We further divided the cohort into those aged $<6$ months or aged $>6$ months, and small trends emerged in univariable analyses (Table 4 ). We noted decreased length of hospital stay in patients aged $>6$ months. Although the relative risk was small, aortic crossclamp time was the only significant predictor of major adverse events in either group (odds ratio [OR], 1.05; 95\% confidence interval [CI], 1.02-1.08). Additionally, age $>6$ months was significantly associated with a decreased risk of transient or permanent heart block (OR, 0.47; 95\% CI, $0.26-0.85$ ), whereas increased weight at operation was associated with a decreased risk of significant postoperative hemorrhage (OR, 0.77; 95\% CI, 0.63-0.94).

\section{Multivariable Model and Predictors of Length of Stay}

Because major adverse outcomes were infrequent, we analyzed length of stay as an important clinical metric.
Indeed, it has recently been shown that length of stay is a strong predictor of neurocognitive outcomes in patients with congenital heart disease, and, certainly, is a driver of inpatient health care costs. Thus, identifying predictors of increased length of stay might provide information to modify practice and change outcomes. We constructed multivariable predictive models of length of stay and discovered a number of interesting observations (Table 5). For patients aged $<6$ months, each 1.0 day of ventilation resulted in a 1.3-day longer length of stay in addition to the ventilated day, whereas every extra $1.0 \mathrm{~kg}$ in operative weight resulted in a 2.3-day shorter length of stay. Finally, the presence of a genetic condition resulted in a 9.4-day longer length of stay. These associations in patients aged $<6$ months were also strongly correlated with Category $\mathrm{Q}$ for operative indication (failure to thrive/congestive heart failure). In patients aged $>6$ months, there were fewer associations. Each 1.0 day of ventilation resulted in a 0.6-day longer length of stay in addition to the ventilated day. The only other

TABLE 4. Analysis of significant variables by age category

\begin{tabular}{lrcr}
\hline \multicolumn{1}{c}{ Predictor } & $\boldsymbol{\beta}$ & $\boldsymbol{R}^{\mathbf{2}}$ & $\boldsymbol{P}$ value \\
\hline$\leq 6$ mo & & & \\
Weight at operation (kg) & -5.48 & 0.042 & $.0086^{*}$ \\
Operative time (min) & 0.16 & 0.077 & $.0003 \dagger$ \\
Perfusion time (min) & 0.46 & 0.200 & $<.0001 \dagger$ \\
Crossclamp time (min) & 0.50 & 0.058 & $.0017^{*}$ \\
Total ventilation time (d) & 1.50 & 0.440 & $<.0001 \dagger$ \\
Genetic diagnosis (yes-no) & 16.6 & 0.069 & $.0007 \dagger$ \\
$>6$ mo & & & \\
Weight at operation (kg) & - & - & .137 \\
Operative time (min) & 0.01 & 0.086 & $.0011^{*}$ \\
Perfusion time (min) & 0.03 & 0.054 & $.0108 \ddagger$ \\
Cross-clamp time (min) & 0.04 & 0.031 & $.0534 \S$ \\
Total ventilation time (d) & 0.67 & 0.190 & $<.0001 \dagger$ \\
Genetic diagnosis (yes-no) & 1.07 & 0.025 & .0856 \\
\hline
\end{tabular}

*P>.001-.01. $\dagger P \leq .001 . \ddagger P>.01-.05 . \S P>.05-.1$. 
TABLE 5. Multivariable model predicting length of stay

\begin{tabular}{lcc}
\hline \multicolumn{1}{c}{ Predictor } & $\beta(\mathbf{d})$ & $\boldsymbol{P}$ value \\
\hline Complete cohort & & \\
$\quad$ Age category $(>6$ mo or $\leq 6 \mathrm{mo})$ & +9.70 & $.0003^{*}$ \\
$\quad$ Indication for operation & - & .385 \\
$\leq 6$ mo & +1.30 & \\
$\quad$ Ventilation time (d) & -2.25 & $<.0001 \dagger$ \\
Weight at operation (kg) & +9.41 & $.0242 \ddagger$ \\
Genetic diagnosis (yes-no) & $.0002 \S$ \\
$>6$ mo & +0.63 & $<.0001 \dagger$ \\
Ventilation time (d) & 0.017 & $.0506 \|$ \\
Operative time (min) & &
\end{tabular}

predictor significant in our multivariable analysis in the older age group was operative time, with each minute of operation time resulting in a 0.17 -day increase in length of stay $(P=.0506)$, suggesting that an expeditious operation should still be considered an important goal.

\section{DISCUSSION}

We are interested in understanding contemporary outcomes of VSD repair in children in the current era. Specifically, we wanted to catalogue how practice has changed over a substantial period in a single large institution, and, more importantly, we wanted to investigate the drivers of morbidity and length of stay in this diverse group of patients. Indeed, although a vast majority of patients undergoing VSD closure do well, there is considerable clinical heterogeneity, and categorization by anatomic defect alone may confound outcome analyses, mixing patients at high and low risk. In addition, there have been surprisingly few analyses of outcomes of VSD closure during the past 10 to 20 years, and even fewer that assess drivers of these outcomes. Thus, we undertook a comprehensive analysis of contemporary VSD closure in an effort to understand current predictors of morbidity and length of stay.

This study examined contemporary outcomes of simple VSD closure at a single large institution. VSD closure continues to be a relatively safe and expeditious operation, with low morbidity and mortality. Despite advances in surgery, perfusion, cardiology, nursing, and critical care, complications continue to plague even the simplest of procedures. Thus, we sought to understand the drivers of morbidity associated with this procedure in a contemporary cohort. There were few components that survived robust statistical interrogation for morbidity and none for mortality. Somewhat surprisingly, there were few changes in practice characteristics over time. For example, there was no significant difference in total ventilation time in any diagnostic category over time. Similarly, there was no significant change in operative time, perfusion time, or crossclamp time for all operative indications during the course of this 7-year study. Not surprisingly, on the other hand, the presence of genetic conditions was strongly associated with increased length of stay. When the cohort was further broken down into those aged $<6$ months or $>6$ months, small trends emerged, with a decreased length of stay in patients aged $>6$ months, independent of weight. In children aged $<6$ months, however, weight remained a strong predictor of outcomes and a driver of length of stay.

One important question that this study cannot completely answer is whether the true driver of morbidity in infants undergoing VSD repair is weight or age. In our cohort, weight and age were highly correlated $(P<.0001)$. This is notable because clinicians regularly face the question of whether to "wait and grow" their patients before operation or to "hurry and operate" so that patients can grow. An analysis of composite risk (ie, ECMO, death, reoperation, pacemaker, or seizure) by age category provides some insights. Patients aged $<6$ months undergoing VSD repair exhibited a 1.8-fold increase in composite risk for each $1.0-\mathrm{kg}$ decrease in weight (OR, 1.80; $P=.037)$. This is in contrast to the relative stability of older patients (aged $>6$ months), in whom there was no significant change in composite risk by weight $(\mathrm{OR}, 0.998 ; P=.952)$, even in patients referred for failure to thrive. This analysis argues that, in the context of a composite risk, in children aged $>6$ months, there is no reason to delay surgery for attempted weight gain. This result correlates well with surgical bias, in which the size of the heart does not significantly reflect the complexity of the repair. It does not, however, answer the more frequent debate of what to do for a 2-month old who fails to grow. Interestingly, neither birth weight nor gestational age had significant affects on composite risk, suggesting that postnatal care and development is at least as important as prenatal care and development.

Although this study provides some valuable insights into the drivers of risk associated with VSD closure in the current surgical era, it has a few notable limitations. First, this represents a single institutional experience that may not be applicable at other sites. Second, the study design was a retrospective chart review, reporting the operative experience of 7 surgeons, with an uneven distribution of cases ( $>98 \%$ of which were performed by the same 3 surgeons). Third, cardiac critical care, nursing, and other essential staff who participated in care of these patients fluctuated dramatically over the course of the study and were not assessed. Fourth, other potentially important predictors of outcomes, such as response to medical treatment before surgery, were not available for our retrospective review, with a large number of patients $(n=84)$ excluded for incomplete data sets (mostly perfusion data). Fifth, our follow-up only extended through the first postoperative clinic visit, which is both a variable and suboptimal time frame to analyze risk for a congenital disease. Lastly, the study does not answer several important questions, such as when to operate on a small infant who fails to grow. This and other questions will be 
important to address in the future, because outcomes for these children plateau. Indeed, this plateau phenomenon is now apparent in many anatomic congenital heart disease subsets. We suggest that nonanatomic information, such as can be derived from complete genomic datasets, may some day provide the keys to understanding this variability.

The authors thank the care providers who contributed to the clinical care of these patients, especially William Gaynor, Marshal Jacobs, William Decampli, and Stephanie Fuller.

\section{References}

1. Bahtiyar MO, Dulay AT, Weeks BP, Friedman AH, Copel JA. Prenatal course of isolated muscular ventricular septal defects diagnosed only by color Doppler sonography: single-institution experience. J Ultrasound Med. 2008;27:715-20.

2. Hoffman JI, Kaplan S. The incidence of congenital heart disease. JAm Coll Cardiol. 2002;39:1890-900.

3. Hoffman JI, Kaplan S, Liberthson RR. Prevalence of congenital heart disease. Am Heart J. 2004;147:425-39.

4. Bol Raap G, Meijboom FJ, Kappetein AP, Galema TW, Yap SC, Bogers AJ. Long-term follow-up and quality of life after closure of ventricular septal defect in adults. Eur J Cardiothorac Surg. 2007;32:215-9.

5. Lillehei CW, Varco RL, Cohen M, Warden HE, Patton C, Moller JH. The first open-heart repairs of ventricular septal defect, atrioventricular communis, and tetralogy of Fallot using extracorporeal circulation by cross-circulation: a 30-year follow-up. Ann Thorac Surg. 1986;41:4-21.
6. Stirling GR, Stanley PH, Lillehei CW. The effects of cardiac bypass and ventriculotomy upon right ventricular function; with report of successful closure of ventricular septal defect by use of atriotomy. Surg Forum. 1957; 8:433-8.

7. Yoshimura N, Matsuhisa H, Otaka S, Kitahara J, Murakami H, Uese K, et al. Surgical management of multiple ventricular septal defects: the role of the felt sandwich technique. J Thorac Cardiovasc Surg. 2009;137:924-8.

8. Wang Q, Li Q, Zhang J, Wu Z, Zhou Q, Wang DJ. Ventricular septal defects closure using a minimal right vertical infraaxillary thoracotomy: seven-year experience in 274 patients. Ann Thorac Surg. 2010;89:552-5.

9. Kaltman JR, Jarvik GP, Bernbaum J, Wernovsky G, Gerdes M, Zackai E, et al. Neurodevelopmental outcome after early repair of a ventricular septal defect with or without aortic arch obstruction. J Thorac Cardiovasc Surg. 2006;131: 792-8.

10. Tucker EM, Pyles LA, Bass JL, Moller JH. Permanent pacemaker for atrioventricular conduction block after operative repair of perimembranous ventricular septal defect. J Am Coll Cardiol. 2007;50:1196-200.

11. Xunmin C, Shisen J, Jianbin G, Haidong W, Lijun W. Comparison of results and complications of surgical and Amplatzer device closure of perimembranous ventricular septal defects. Int J Cardiol. 2007;120:28-31.

12. Saleem K, Ahmad SA, Rashid A, Khan AA, Zameer M, Naqvi S, et al. Outcome of ventricular septal defect closure. J Coll Physicians Surg Pak. 2004;14:351-4.

13. Scully BB, Morales DL, Zafar F, McKenzie ED, Fraser CD Jr, Heinle JS. Current expectations for surgical repair of isolated ventricular septal defects. Ann Thorac Surg. 2010;89:544-9; discussion 50-1.

14. Kogon B, Butler H, Kirshbom P, Kanter K, McConnell M. Closure of symptomatic ventricular septal defects: how early is too early? Pediatr Cardiol. 2008;29: 36-9.

15. Sondheimer HM, Rahimi-Alangi K. Current management of ventricular septal defect. Cardiol Young. 2006;16(Suppl 3):131-5.
APPENDIX TABLE 1. Patient and hospital characteristics $(n=285)$

\begin{tabular}{lc}
\hline \multicolumn{1}{c}{ Variable } & Mean \pm SD/median $(\mathbf{m i n} / \mathbf{m a x})$ \\
\hline Age $(\mathrm{d})$ & $482.9 \pm 1258.3 / 144.0(16.0-17,708.0)$ \\
Weeks gestation & $38.1 \pm 2.9 / 40.0(28.0-41.2)$ \\
Weight $(\mathrm{kg})$ & \\
$\quad$ Birth & $2.9 \pm 0.7 / 3.0(0.9-4.4)$ \\
$\quad$ At operation & $7.6 \pm 7.8 / 5.1(1.5-73.8)$ \\
Hospitalization (d) & \\
$\quad$ Total & $9.2 \pm 22.7 / 3.0(1.0-271.0)$ \\
$\quad$ Postoperative & $6.5 \pm 17.5 / 3.0(1.0-269.0)$ \\
Mechanical ventilation $(\mathrm{d})$ & \\
$\quad$ Preoperative & $1.0 \pm 6.5 / 0(0-70.0)$ \\
Postoperative & $0.7 \pm 2.2 / 0(0-19.0)$ \\
\hline
\end{tabular}

$S D$, Standard deviation. 
APPENDIX TABLE 2. Age distribution by reason for operation*

\begin{tabular}{lcccc}
\hline Age category (mo) & FTT/CHF (category Q) & RVOTO/AI/DCRV (category O) & PHTN (category P) & Total n (\%) \\
\hline$\leq 6$ & $150(64.6)$ & $1(3.2)$ & $13(59.1)$ & $164(58.2)$ \\
$>6$ & $82(35.3)$ & $30(96.8)$ & $9(40.9)$ & $118(41.8)$ \\
Median age in days & $339 \pm 1225 /(16.0-17,708.0)$ & $1588 \pm 1316 /(108.0-4824.0)$ & $408 \pm 773 /(19.0-3639.0)$ & $483 \pm 1258 /(16.0-17,708.0)$ \\
$\quad \pm \mathrm{SD} /(\min -\max )$ & & & &
\end{tabular}

Based on analysis of variance, $P<.0001\left(R^{2}, 0.095\right) . F T T / C H F$, Failure to thrive/congestive heart failure; RVOTO/AI/DCRV, right ventricle outflow tract obstruction/aortic insufficiency/double chambered right ventricle; PHTN, pulmonary hypertension; $S D$, standard deviation. *Indication for operation was classified in 1 of 3 mutually exclusive groups: FTT/CHF (Category Q: "Flow”); RVOTO/AI/DCRV (Category O: “Obstruction”); and elevated pulmonary vascular resistance (Category P: "Pulmonary").

APPENDIX TABLE 3. Practice variability over time, by operative indication

\begin{tabular}{|c|c|c|c|c|c|c|c|c|}
\hline \multirow[b]{2}{*}{ Variable } & \multicolumn{2}{|c|}{ Overall $(n=285)$} & \multicolumn{2}{|c|}{ Category $Q(n=232)$} & \multicolumn{2}{|c|}{ Category $P(n=22)$} & \multicolumn{2}{|c|}{ Category $O(n=31)$} \\
\hline & $R^{2}$ & $P$ value & $R^{2}$ & $P$ value & $R^{2}$ & $P$ value & $R^{2}$ & $P$ value \\
\hline \multicolumn{9}{|l|}{$\leq 6 \mathrm{mo}$} \\
\hline Total operation time & 0.003 & .459 & 0.0067 & .320 & 0.0017 & .895 & - & - \\
\hline Perfusion time & 0.011 & .177 & 0.0089 & .251 & 0.0032 & .853 & - & - \\
\hline Crossclamp time & 0.003 & .499 & 0.0014 & .644 & 0.019 & .651 & - & - \\
\hline MUF time & 0.075 & $.001 *$ & 0.072 & $.001 *$ & 0.20 & .125 & - & - \\
\hline Total vent time & 0.001 & .768 & 0.0054 & .378 & 0.040 & .510 & - & - \\
\hline Total hospital time & 0.007 & .290 & 0.0051 & .386 & 0.036 & .537 & - & - \\
\hline \multicolumn{9}{|l|}{$>6 \mathrm{mo}$} \\
\hline Total operation time & 0.019 & .133 & 0.015 & .280 & 0.63 & $.011 \dagger$ & 0.00061 & .897 \\
\hline Perfusion time & 0.006 & .404 & 0.014 & .305 & 0.51 & $.031 \dagger$ & 0.028 & .375 \\
\hline Crossclamp time & 0.009 & .298 & 0.0087 & .413 & 0.15 & .311 & 0.043 & .269 \\
\hline Pre-MUF hematocrit & 0.016 & .178 & 0.070 & $.021 \dagger$ & 0.31 & .117 & 0.0059 & .699 \\
\hline Post-MUF hematocrit & 0.025 & $.096 \ddagger$ & 0.11 & $.003 *$ & 0.082 & .455 & 0.0015 & $.041 \dagger$ \\
\hline MUF time & 0.020 & .140 & 0.15 & $.001 *$ & 0.14 & .312 & 0.058 & .227 \\
\hline Total vent time & 0.005 & .458 & 0.025 & .165 & 0.086 & .443 & 0.077 & .137 \\
\hline Total hospital time & 0.070 & $.004 *$ & 0.037 & $.089 \ddagger$ & 0.43 & $.054 \ddagger$ & 0.10 & $.089 \ddagger$ \\
\hline
\end{tabular}

Indication for operation was classified in 1 of 3 mutually exclusive groups: failure to thrive/congestive heart failure (Category Q: "Flow"); right ventricular obstruction, aortic insufficiency, or double chamber right ventricle (Category O: "Obstruction"); and elevated pulmonary vascular resistance (Category P: "Pulmonary"). MUF, Modified ultrafiltration. $* P \leq .01 . \dagger P>.01-.05 . \ddagger P>.05-.10$. 